\title{
Uma nova edição crítica da Bíblia Hebraica
}

\author{
A new critical edition of the Hebrew Bible
}

Cássio Murilo Dias da Silva

\section{Resumo}

Este artigo tem como finalidade apresentar o novo fascículo da obra multivolume Biblia Hebraica Quinta (BHQ), sucessora da Biblia Hebraica Stuttgartensia $(B H S)$. Antes de apresentar o projeto editorial da $B H Q$ (ainda incompleto, com apenas oito fascículos publicados dos vinte e três programados), este artigo explica por que esta nova edição crítica da Bíblia Hebraica é chamada de "Quinta". Para isso, percorre rapidamente o histórico das edições críticas anteriores $\left(B H K^{1-2-3}\right.$ e $\left.B H S\right)$. Em seguida, faz uma apresentação geral do projeto da $B H Q$ e a compara com a $B H S$, nos seguintes aspectos: o aparato crítico e o comentário a ele, as massorás e as notas a elas. $\mathrm{O}$ aparato crítico, totalmente reformulado, tem novas siglas, utiliza novos manuscritos e, graças às novas tecnologias gráficas, incorpora novos recursos. Uma sessão dedicada a discutir as variantes textuais traz uma síntese do veredito do comitê editorial para cada caso contemplado no aparto crítico. As duas massorás (a magna e a parva) são igualmente discutidas e comentadas em sessões específicas de cada fascículo. Para que o leitor compreenda com mais clareza as mudanças desta nova edição crítica, o artigo toma como exemplo o caso de Lv 1,7: são transcritas e traduzidas algumas porções do fascículo, que deixam claros os avanços na discussão e na avaliação dos manuscritos, bem como a nova diagramação e os novos recursos disponibilizados na $B H Q$.

Palavras-chave: Bíblia Hebraica. Levítico. Aparato crítico. Crítica textual. Massorá. 


\section{Abstract}

The purpose of this article is to present the new issue of the multivolume Biblia Hebraica Quinta (BHQ), successor to the Biblia Hebraica Stuttgartensia $(B H S)$. Before presenting the editorial project of $B H Q$ (still incomplete, with only eight issues published out of the twenty-three scheduled), this article explains why this new critical edition of the Hebrew Bible is called "Fifth". For this purpose, it briefly runs through the history of the previous critical editions $\left(B H K^{1-2-3}\right.$ and $\left.B H S\right)$. Then, it gives a general presentation of the $B H Q$ project and compares it to the $B H S$ in the following aspects: the critical apparatus and the commentary to it, the masoras and the notes to them. The completely redesigned critical apparatus has new acronyms, uses new manuscripts, and, thanks to new graphic technologies, incorporates new features. A session dedicated to discussing textual variants provides a synthesis of the editorial committee's verdict for each case contemplated in the critical apparatus. The two masoras (the magna and the parva) are also discussed and commented on in specific sessions of each issue. In order to make clear to the reader the changes in this new critical edition, the article takes as an example the case of Lv 1,7: some portions of the issue are transcribed and translated, which make clear the advances in the discussion and evaluation of the manuscripts, as well as the new layout and resources made available in $B H Q$.

Keywords: Hebrew Bible. Leviticus. Critical apparatus. Textual criticism. Masora.

\section{Introdução}

O texto bíblico: não há dois manuscritos exatamente iguais da primeira à última linha; bem provavelmente, não há um único versículo transcrito exatamente do mesmo modo em todos os manuscritos. Somente com o advento da imprensa, no século XV, o texto de ambos os Testamentos canônicos (Antigo e Novo ${ }^{1}$ ) tornou-se estável e as mudanças operadas pelos copistas - tanto as involuntárias/inconscientes (erros de ouvido, haplografias, ditografias, paráblepsis, metáteses e confusões de letras) quanto as voluntárias/conscientes

\footnotetext{
${ }^{1}$ Para uma discussão sobre a nomenclatura "Primeiro" e "Segundo" Testamentos e meus argumentos contra ela, ver SILVA, C. M. D. da, "Novo" ou "Segundo" Testamento?
} 
(glosas e mudanças por razões teológicas) - deixaram de se multiplicar.

Não tardou para que intelectuais judeus preparassem e imprimissem livros com características do que hoje é chamado de "edições críticas". A princípio eram publicadas em porções e, posteriormente, coligidas. Já a partir da segunda metade do século XV e, com ainda maior força e velocidade, no século XVI, as edições dos textos da Sagrada Escritura judaica espalharam-se pela Europa. ${ }^{2}$ Além do texto hebraico, tais publicações traziam também comentários rabínicos e traduções aramaicas. Paralelamente, os cristãos também publicaram os livros do seu cânon em versões poliglotas, com textos em hebraico, grego, latim, aramaico, siríaco etc.

Desde essas primeiras publicações, tornou-se claro que os avanços tecnológicos traziam forte impacto não apenas na edição do texto bíblico, mas também na sua preservação. É natural, portanto, que as inovações das décadas recentes surtam efeitos equivalentes. Com as possibilidades trazidas principalmente pela informática, tornou-se possível a publicação de novas e mais acuradas edições críticas, tanto da Bíblia Hebraica como do Novo Testamento. ${ }^{3}$ Graças a novas ferramentas e circunstâncias, no final de 2020, foi lançado o terceiro fascículo da monumental obra Biblia Hebraica Quinta, dedicado ao livro do Levítico. Esta é uma apresentação breve, mas sistemática, da edição crítica sucessora da consagrada e muito conhecida Biblia Hebraica Stuttgartensia. Para compreender a importância desta nova publicação para a crítica textual do Antigo Testamento é necessário percorrer brevemente o seu histórico e confrontá-la com a edição crítica que a precedeu.

\section{Por que "Quinta"?}

No título geral da publicação - Biblia Hebraica Quinta (dovarante, $B H Q)$ - o especificador "Quinta" decorre do histórico das edições anteriores.

\footnotetext{
${ }^{2}$ Para uma lista das primeiras edições judaicas, com locais, datas e editores, ver FRANCISCO, E. F., Manual da Bíblia Hebraica, p. 342-343. No restante do terceiro capítulo (p. 342-381), Francisco apresenta com alguns detalhes as edições do Texto Massorético até as primeiras décadas do século XXI.

${ }^{3}$ Para o Novo Testamento, a Editio Critica Maior, publicada pelo Institut für Neutestamentliche Textforschung der Universität Münster. Para os volumes até agora publicados, ver as referências bibliográficas ao final deste artigo. Ver também minha recensão sobre o terceiro volume em SILVA, C. M. D. da. INSTITUT für Neutestamentliche Textforschung. Novum Testamentum Graecum: Editio Critica Maior - III: Die Apostelgheschichte / The Acts of Apostles.
} 
As três primeiras são conhecidas como Biblia Hebraica Kittel, graças a Rudolf Kittel, que, entre 1906 e 1913, publicou as duas primeiras versões, chamadas, respectivamente, de $B H K^{1}$ e $B H K^{2}$. Ambas eram baseadas na Bíblia rabínica conhecida como Mikraot Gedolot, publicada por Jacob ben Hayyim ibn Adonijah, em Veneza, em 1524-1525. A terceira edição $\left(B H K^{3}\right)$ foi publicada em fascículos entre 1929 (ano da morte de Kittel) e 1937. Para esta nova publicação, Kittel adotou o Códice Leningradense, isto é, o manuscrito B19A, de 1008, com a sua massorá marginal (Masorah Parva). ${ }^{4}$

A destruição do material gráfico durante a Segunda Grande Guerra e a descoberta de novos manuscritos exigiram todo um novo projeto editorial para uma nova publicação. Assim, entre 1968 e 1976, foram publicados os fascículos Biblia Hebraica Stuttgartensia (dovarante, BHS), que equivale, portanto, à quarta edição da série de edições críticas iniciadas por Kittel. ${ }^{5} \mathrm{O}$ volume completo foi lançado em um único tomo em 1977.

Não obstante a $B H S$ seja uma edição crítica madura e consolidada, ela não sofreu grandes atualizações e correções desde seu lançamento. ${ }^{6}$ A última atualização da $B H S$ ocorreu na quinta edição, em $1997 .{ }^{7}$ No prefácio a esta edição revista, Adrian Schenker esclarece que foram eliminados "erros do texto, do segundo aparato crítico e da massorá", 8 indicados por numerosos pesquisadores. Além disso, o glossário das abreviações latinas foi totalmente reelaborado.

Os fatores que tornaram obrigatória a publicação de um novo texto crítico são basicamente três. Em primeiro lugar, as descobertas, nos últimos cinquenta anos, de novos manuscritos. Tal fato, por si só, obrigava a uma contínua reavaliação dos que já eram conhecidos. Segundo, os avanços da exegese tiveram impactos na discussão da crítica textual. Por fim, as novas ferramentas trazidas pela informática: tratamento digital de imagens, comparação de manuscritos, estatística e acesso facilitado a dados. Este novo contexto exegético e tecnológico deixou claro que não bastaria uma edição "remendada" da BHS: era necessária uma publicação totalmente nova, com novo aparato crítico e novo tratamento das variantes.

\footnotetext{
${ }^{4}$ WIKIPEDIA, Biblia Hebraica (Kittel).

${ }^{5}$ KITTEL, R.; KAHLE, P. E. (Eds.)., Biblia Hebraica.

${ }^{6}$ Para história da BHS e de sua antecessora, a Bíblia Hebraica Kittel (BHK), ver as páginas de Prolegômenos da própria $B H S$, em vários idiomas, conforme a publicação. A tradução em português encontra-se também em FRANCISCO, E. F., Manual da Bíblia Hebraica, p. 3-15.

${ }^{7}$ ELLIGER, K.; RUDOLPH, W. (Eds.)., Biblia Hebraica Stuttgartensia.

${ }^{8} B H S$ - Prolegomena, p. III (alemão), XI (inglês), XIX (francês), XXIX (espanhol) e XXXVIII (latim).
} 


\section{Muito além de uma atualização}

Embora os editores mantenham o Códice Leningradense B19A como o manuscrito hebraico de base, a $B H Q$ é bem mais do que uma modernização da $B H S$. Após anos de preparação e pesquisa, em 2004, foi publicado o primeiro fascículo da $B H Q$. Tal como ocorrera na publicação em fascículos da $B H K^{3} \mathrm{e}$ da $B H S$, o primeiro tomo publicado não equivale ao "fascículo 1 " da coleção, isto é, o livro do Gênesis. A publicação da $B H Q$ começou com o fascículo 18 , dedicado às cinco Megilloth ${ }^{9}$ (Rute, Cântico dos Cânticos, Qohélet, Lamentações e Ester). Posteriormente, foram lançados: em 2006, Esdras e Neemias (fascículo 20); em 2007, Deuteronômio (fascículo 5); em 2008, Provérbios (fascículo 17); em 2010, Os Doze Profetas Menores (fascículo 13); em 2011, Juízes (fascículo 7); em 2015, Gênesis (fascículo 1); em 2020, Levítico (fascículo 3). ${ }^{10}$

Quando concluída, a $B H Q$ será composta por vinte fascículos que serão agrupados em dois volumes. O primeiro seguirá o padrão já presente nas três edições da $B H K$ e na $B H S$ : o texto hebraico, as massorás e o aparato crítico, bem como a introdução geral, as opções editoriais (siglas, símbolos e abreviações). O segundo volume trará as introduções específicas para cada livro, os comentários ao texto e ao aparato crítico, bem como as traduções e as notas às massorás (Masorah Parva e Masorah Magna).

Quem está habituado a ler e consultar a $B H S$ fica impressionado apenas ao ter contato visual com os volumes da $B H Q$. Para tomar como exemplo unicamente o livro do Levítico, bastam alguns números. Na $B H S$, o texto, as massorás e o aparato crítico do terceiro livro do Pentateuco ocupam exatas cinquenta páginas. Muito diferente é a $B H Q$ : o volume dedicado unicamente ao Levítico tem mais de duzentos e cinquenta páginas (às quais se devem acrescentar outras trinta com o elenco e a explicação das siglas, dos termos técnicos e de outras informações técnicas e gráficas da publicação). Convém, portanto, explicar com mais detalhes o que é a $B H Q$.

\footnotetext{
${ }^{9}$ Plural de megillah, palavra hebraica (feminina) que significa "livrinho". Cada uma das cinco Megilloth é associada a uma festa judaica: o livro de Ester é lido na festa de Purim; Cântico dos Cânticos, na Páscoa; Rute, em Pentecostes; Qohélet, em Sukkôt; Lamentações, na comemoração da queda de Jerusalém sob os babilônios.

${ }^{10}$ Para indicações mais completas sobre cada fascículo da $B H Q$ publicado, ver as referências bibliográficas ao final deste atrigo.
} 
Cada fascículo deve ser lido em duas direções: da direita para a esquerda e da esquerda para a direita. Nas páginas da direita para a esquerda, encontramse dois tipos de numeração. Nas páginas com algarismos romanos, as informações técnicas de praxe (siglas, abreviações, definições e símbolos utilizados na publicação). Nas páginas com números indo-arábicos simples, o texto hebraico, com as massorás e o aparato crítico.

As páginas da esquerda para a direita são numeradas com algarismos indo-arábicos seguidos por um asterisco $\left(^{*}\right)$. Nelas identificam-se cinco seções:

a) a introdução ao volume e três apêndices, centrados nos manuscritos (testemunhos) que serviram de base para a edição;

b) as notas sobre casos difíceis da Masorah Parva;

c) as notas sobre casos difíceis da Masorah Magna;

d) um abrangente comentário ao aparato crítico;

e) uma longa bibliografia, com as obras citadas no comentário.

Este novo projeto editorial e várias decisões assumidas nele decorrem do público para o qual a $B H Q$ é direcionada primariamente:

$\mathrm{O}$ público principal e pretendido do $\mathrm{BHQ}$ são pessoas que não são especialistas na crítica textual da Bíblia Hebraica, mas que precisam de uma edição acadêmica, para não dizer crítica, de seu texto. Este grupo inclui estudiosos de vários tipos, tradutores da Bíblia, clérigos e estudantes. ${ }^{11}$

A seguir, apresento brevemente as seguintes seções desta nova edição crítica: o aparato crítico, o comentário ao aparato crítico, as notas à Masorah Parva e à Masorah Magna.

\section{Um novo aparato crítico}

Quem costuma pesquisar e discutir as diferenças textuais entre os manuscritos do Antigo Testamento já se habituou às siglas e aos códigos da $B H S$, bem como à diagramação peculiar do seu aparato crítico. Tal pesquisador(a), porém, ao abrir a $B H Q$, está diante de um novo universo. Tal como na $B H S$, o aparato crítico da $B H Q$ apresenta as variantes mais significativas para a tradução e a exegese. Não obstante, as siglas, os símbolos e as abreviações da $B H Q$ diferem muito do que é utilizado na $B H S$. Além disso,

${ }^{11}$ WEIS, R. D., Biblia Hebraica Quinta and the Making of Critical Editions of the Hebrew Bible. 
as novas tecnologias gráficas possibilitam que porções do texto siríaco estejam escritas com aquele alfabeto, e não mais transliteradas, como na $B H S$. Para que o leitor deste artigo possa visualizar o novo aparato crítico e confrontá-lo com o da $B H S$, tomo como exemplo Lv 1,7 .

No texto da $B H S$, as palavras ou frases com variantes arroladas no aparato crítico são marcadas com letras latinas minúsculas sobrescritas ( ${ }^{\mathrm{a}} \mathrm{b} \mathrm{c}$

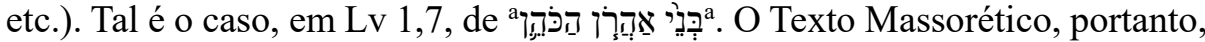
lê: "os filhos de Aarão, o sacerdote". As duas letras a sobrescritas remetem ao aparato crítico que, para esta frase, traz a seguinte notação:

$$
7^{\text {a-a }} \text { S khn' bnj 'hrwn = הכהנים ב' א' cf 5.8.11 etc.; > V }
$$

No sistema da $B H S$, isso significa que a versão siríaca lê "os sacerdotes filhos de Aarão", em harmonia com o sintagma presente nos versículos 5, 8 e 11, entre outros. Na Vulgata, porém, aqui há uma lacuna.

Bem diferentes são as notações da $B H Q$. O texto (p. 3-91) é limpo, sem a inserção de caracteres latinos que remetam ao aparato crítico. Neste, cada palavra ou frase discutida é transcrita integralmente, seguida pelas siglas, abreviações e variantes. Para o caso aqui tomado como exemplo, na p. 3, encontra-se:

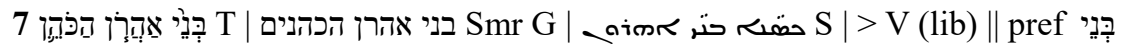 Smr G}

No sistema da $B H Q$, essas notações significam que, em todas as versões do Targum, a leitura é a mesma do Texto Massorético; no Pentateuco Samaritano e na Bíblia Grega, a última palavra desta frase está no plural e com artigo: "os sacerdotes", a mesma leitura da versão Siríaca: "os filhos de Aarão, os sacerdotes" ou "os sacerdotes filhos de Aarão". Na Vulgata, que traduziu com liberdade, há uma lacuna. $\mathrm{O}$ editor do fascículo, sugere que se prefira a leitura do Pentateuco Samaritano e da Bíblia Grega. O último símbolo $(\square)$ indica que se trata de um caso discutido com mais profundidade no comentário ao aparato crítico.

\section{Comentário ao aparato crítico}

Em outra seção do fascículo, um comentário avalia casos selecionados e explica as razões que levaram o comitê editor a sugerir que o pesquisador ou 
tradutor mantenha o texto do Códice Leningradense ou, diferente, assuma outra leitura. No fascículo de Levítico, o comentário ao aparato crítico ocupa as páginas $57 *-133 *$. O exemplo aqui apresentado, encontra-se na p. 58*. Assim:

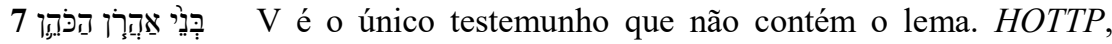
1:161, preferiu o singular de $\mathrm{M}$ ao plural do Smr e G. Neste caso, a leitura de Smr e $\mathrm{G}$ pode ser caracterizada como uma harmonização com Lv 1,5.8.11. M poderia ser também o resultado de um erro, como pensam Milgrom (Leviticus 1-16,157) e Hartley (Leviticus, 13). A forma singular de M (הכהן) foca em Aarão, não em seus filhos (ver outras ocorrências na $\mathrm{Mm}$ ). Esta leitura está em conflito com o contexto de Levítico, no qual o foco está sobre os filhos de Aarão como sacerdotes. Assim, Smr e G podem representar a lição mais antiga e preferível. S é um acordo com Smr e G, ainda que suas palavras estejam em ordem invertida (ver o comentário sobre 1,5$){ }^{12}$

O comentário simplifica muito o trabalho do exegeta e do tradutor, uma vez que traz já pronta a análise e a avaliação dos principais casos com variantes, seguindo os passos da crítica textual clássica (crítica externa e crítica interna). Para os casos não contemplados no comentário, compete ao exegeta ou tradutor fazer sua própria avaliação, baseado no procedimento adotado pelos editores para os casos estudados, que servem de guia para ler e analisar a gama de informações do aparato crítico. Por outro lado, tanto para os casos estudados, como para os não estudados, é sempre útil consultar as notas às duas massorás: à Masorah Parva (páginas $21 *-41$ *) e à Masorah Magna (páginas 43*-55*).

\section{As massorás}

Embora baseadas no mesmo manuscrito, $B H S$ e $B H Q$ possuem diferentes massorás. Para o caso analisado em Lv 1,7, a massorá marginal (Masorah Parva) da $B H S$ traz a seguinte notação: ${ }^{10}$ ¿. A letra Guímel encimada por um ponto é o numeral 3 em hebraico. $\mathrm{O}$ número $10 \mathrm{em}$ sobrescrito remete o exegeta às listas da Masorah Magna, encontrada no primeiro registro no rodapé, entre o texto e as variantes do aparato crítico. Nela, encontra-se a notação ${ }^{10} \mathrm{Mm} 661$. Traduzindo

\footnotetext{
${ }^{12}$ As referências bibliográficas de obras e autores citados no comentário encontram-se na vasta bibliografia das p. $135 *-147 *$.
} 
tudo: o sintagma assinalado pelo pequeno círculo no texto é utilizado unicamente três vezes (ג) no Códice Leningradense, e tais ocorrências estão arroladas na lista 661 da Massorah Gedolah, publicada por Gérard E. Weil. ${ }^{13}$

$\mathrm{Na} \mathrm{BHQ}$, as mesmas informações são noticiadas diferentemente. A massorá marginal traz unicamente um $\dot{\xi}$, a tradicional notação massorética para uma palavra ou frase única (isto é, um hápax legómenon) no livro ou em toda a Bíblia Hebraica. Não há, porém, nenhuma numeração que remeta às listas da Masorah Magna no primeiro registro no rodapé. Em lugar, o exegeta encontra o seguinte:

\section{[7] בני אהרן הכהן ג ונתנו . ויצא הגורל למשפחת הקהתי . ודבתר}

Traduzindo:

- "os filhos de Aarão o sacerdote", isto é, a frase em discussão.

$-\dot{\lambda}=$ o numeral 3 em hebraico, isto é, três vezes.

- ונתנת = primeiro verbo de Lv 1,7: "e porão, atearão (fogo)".

o início de Js 21,4: "e a sorte saiu para a família dos coatitas".

- conforma o glossário das p. XXVII-XXIX, "e depois disso", isto é, logo em seguida. Ou seja, Js 21,13.

Estas palavras e frases em hebraico são a transcrição das informações da lista 661 da Massorah Gedolah de Weil.

A comparação de ambas as edições críticas revela que o sistema de informações da $B H S$ é bastante compacto, mas que torna o exegeta dependente de ter acesso a uma edição da obra de Weil. Por sua vez, a Masorah Magna da $B H Q$ contempla um número bem menor de casos e transcreve, em hebraico, a mesma lista 661. Não obstante, tal transcrição deixaria ainda assim o exegeta dependente da Massorah Gedolah, não fossem as notas às massorás, nas p. 21*-55*.

\section{Notas às massorás}

Para o exemplo aqui oferecido, a nota para a Masorah Parva (p. 21*) observa:

${ }^{13}$ WEIL, G. E., Massorah Gedolah Iuxta Codicem Leningradensem B 19 a. 


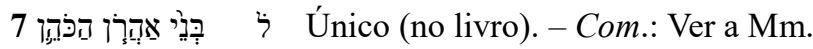

A nota se limita a traduzir a notação da massorá marginal (a Masorah Parva): a letra Lamed encimada por um ponto (ל) indica que o sintagma assinalado - com הפכהן [o sacerdote] no singular - é único no livro. Isto é, um hapax legómenon em Levítico. Para um comentário a esta informação, o exegeta é remetido à nota para a Masorah Magna, na p. 43*, onde ele encontra:

:הכהן אהרן בני 7 : Três vezes (em formas correlatas): Lv 1,7; Js 21,4; e outra logo em seguida $(21,13)$. - Com.: A Mm para este caso encontra-se no rodapé do fólio precedente (fol. $56 \mathrm{v}$ ).

A nota começa com a tradução do que, em hebraico, está na Masorah Magna, entre o texto e o aparato crítico: este sintagma, com הפכּה [o sacerdote] no singular, é encontrado uma única vez no livro do Levítico $($ em 1,7) e apenas outras duas vezes, em Js 21,4.13, no restante do Códice Leningradense. A seguir, um comentário adicional a respeito de onde, no Códice Leningradense B19A se encontra a Masorah Magna para Lv 1,7: no final do verso da página precedente: fólio 56v.

Para este caso específico, que não envolve questões mais intrincadas de crítica textual, a nota é bastante enxuta. Para outros versículos, porém, as notas às duas massorás são mais longas e detalhadas, com a discussão das variantes e a citação de autores e opiniões.

Os dois conjuntos de notas, portanto, não apenas ajudam o exegeta e o tradutor a ler com mais rapidez as massorás da seção, mas também oferecem uma síntese da discussão de uma variante, o que economiza muita pesquisa, além de remeter pontualmente às obras e artigos enumerados na preciosa bibliografia das p. $135^{*}-147^{*}$.

\section{Conclusão}

As novas ferramentas do mundo digital tiveram um enorme impacto no estudo de textos e de manuscritos bíblicos: facilidade de acesso a fotografias de manuscritos, tratamento de imagens, comparação de testemunhos escritos, uso de fontes com caracteres das línguas orientais, recursos gráficos etc. Esta nova realidade tecnológica, aliada ao avanço das pesquisas na área da crítica textual, abriu novas possibilidades para uma nova edição crítica da Bíblia Hebraica. 
Assim como o que havia ocorrido com a $B H S$, que não foi apenas uma $B H K$ com roupagem nova, a $B H Q$ não é uma $B H S$ atualizada: é, na verdade, uma edição bem mais audaciosa.

Nas $B H S$, as letras latinas no meio do tex to hebraico serviam para indicar as variantes arroladas no aparato crítico. Embora não se confundissem com o hebraico, tornavam o texto muito carregado. A eliminação de tais elementos simplifica em muito a leitura do Texto Massorético, pois ele está limpo e mais amigável aos olhos.

Mais amigável é também o novo aparato crítico: a apresentação das variantes é mais detalhada, os testemunhos são mais abundantes e o sistema de notação recebeu aprimoramentos. Na nova diagramação, o aparato crítico e a Masorah Magna chegam a preencher mais da metade de cada página. Diferentemente, na $B H S$, esses dois elementos ocupavam o mínimo espaço possível ao pé da página, em caracteres por vezes tão minúsculos que, para lêlos com clareza, era necessário o auxílio de uma lupa.

A nova apresentação da Masorah Magna - com a transcrição das listas da Massorah Gedolah de Weil - parece supor que o exegeta tenha acesso a concordâncias eletrônicas, o que torna desnecessário arrolar todos os casos, mas apenas os mais significativos.

As notas às massorás, como já afirmado, simplificam muito os labores de exegese e tradução, pois permitem uma rápida leitura e compreensão daquelas informações e, em alguns casos, trazem a discussão acerca de uma variante. Nesta mesma linha segue o comentário ao aparato crítico: a discussão das principais variantes explica a opção feita pelo comitê editor e oferece os critérios para que o exegeta ou tradutor avalie por si mesmo as possibilidades. Tanto as notas às massorás quanto o comentário ao aparato crítico remetem pontualmente a obras (dicionários, livros, artigos) citadas na bibliografia que, por si só, tem altíssimo valor: nela o exegeta e o tradutor encontram, em um único lugar, as referências do que há de mais relevante e atualizado para aprofundar o debate.

À medida que os fascículos são publicados, o comitê editor recebe observações e correções a serem aplicadas para a publicação em dois volumes: um para o texto hebraico, as massorás e o aparato crítico; outro para as introduções específicas para cada livro, os comentários ao texto e as notas às massorás.

Quando completa, a $B H Q$ será obra indispensável e insubstituível na biblioteca de quem deseja traduzir, discutir e interpretar o texto da Bíblia 
Hebraica. Já hoje, enquanto ainda são publicados os fascículos, o exegeta que deseja se manter atualizado não pode se furtar a migrar da $B H S$ para a $B H Q$, uma passagem necessária e inevitável. A $B H S$, com tudo o que devemos a ela, está destinada a ser uma edição histórica, que marcou época, mas que deve ceder lugar a uma sucessora ainda melhor, que também fará história até que, por sua vez, for substituída pela "Biblia Hebraica Sexta" (BH6?). Por ora, os fascículos da $B H Q$ são como um delicioso jantar servido aos poucos: esperar que chegue a refeição completa para só depois iniciar a saborear cada prato é o mesmo que renunciar a degustar cada iguaria com calma, satisfação e deleite.

\section{Referências bibliográficas}

ELLIGER, K.; RUDOLPH, W. (Eds.). Biblia Hebraica Stuttgartensia. 5.ed. Stuttgart: Deutsch Bibelgesellschaft, 1997.

FRANCISCO, E. F. Manual da Bíblia Hebraica. 3.ed. São Paulo: Vida Nova, 2017.

INSTITUT Für Neutestamentliche Textforschung der Universität Münster. Novum Testamentum Graecum - Editio Critica Maior. 2.ed. Stuttgart: Deutsche Bibelgesellschaft, 2013. v. IV: Catholic Letters (2 tomos).

INSTITUT Für Neutestamentliche Textforschung der Universität Münster. Novum Testamentum Graecum - Editio Critica Maior. Stuttgart: Deutsche Bibelgesellschaft, 2017. v. III: Die Apostelgeschichte / Acts of the Apostles (4 tomos).

INSTITUT Für Neutestamentliche Textforschung der Universität Münster. Novum Testamentum Graecum - Editio Critica Maior. Stuttgart: Deutsche Bibelgesellschaft, 2021. v. I: Die Synoptischen Evangelien: Das Markusevangelium (3 tomos).

KITTEL, R.; KAHLE, P. E. (Eds.). Biblia Hebraica. 16.ed. Stuttgart: Württembergische Bibelanstalt, 1973.

SCHENKER, A. et al (Eds.); GELSTON, A. (Prep.). Biblia Hebraica Quinta. Stuttgart: Deutsche Bibelgesellschaft, 2010. Fascicle 13: The Twelve Minor Prophets.

SCHENKER, A. et al (Eds.); MARCOS, N. F. (Prep.). Biblia Hebraica Quinta. Stuttgart: Deutsche Bibelgesellschaft, 2011. Fascicle 7: Judges. 
SCHENKER, A. et al (Eds.); MARCUS, D. (Prep.). Biblia Hebraica Quinta. Stuttgart: Deutsche Bibelgesellschaft, 2006. Fascicle 20: Ezra and Nehemiah.

SCHENKER, A. et al (Eds.); MCCARTHY, C. (Prep.). Biblia Hebraica Quinta. Stuttgart: Deutsche Bibelgesellschaft, 2007. Fascicle 5: Deuteronomy.

SCHENKER, A. et al (Eds.); TAL, A. (Prep.). Biblia Hebraica Quinta. Stuttgart: Deutsche Bibelgesellschaft, 2015. Fascicle 1: Genesis.

SCHENKER, A. et al (Eds.); WAARD, J. De (Prep.). Biblia Hebraica Quinta. Stuttgart: Deutsche Bibelgesellschaft, 2008. Fascicle 17: Proverbs.

SCHENKER, A. et al (Eds.); WAARD, J. De et al (Prep.). Biblia Hebraica Quinta. Stuttgart: Deutsche Bibelgesellschaft, 2004. Fascicle 18: Megilloth.

SCHENKER, A.; WEIS, R. D. et al (Eds.); HIMBAZA, I. (Prep.). Biblia Hebraica Quinta. Stuttgart: Deutsch Bibelgesellschaft, 2020. Fascicle 3: Leviticus.

SILVA, C.M.D. da. "Novo" ou "Segundo" Testamento? Estudo Bíblicos, v. 32, n. 126, p. 225-244, abr./jun. 2015. Disponível em: $<$ https://revista.abib.org.br/EB/article/view/190/190>. Acesso em: 5 nov. 2021.

SILVA, C.M.D. da. INSTITUT für Neutestamentliche Textforschung. Novum Testamentum Graecum: Editio Critica Maior - III: Die Apostelgheschichte / The Acts of Apostles. Recensão. Perspectiva Teológica, v. 49, n. 3, p. 703 707, set./dez. 2017.2 Disponível em: $<$ http://www.faje.edu.br/periodicos/index.php/perspectiva/article/view/3895/3 907>. Acesso em: 8 nov. 2021.

WEIL, G. E. Massorah Gedolah Iuxta Codicem Leningradensem B 19 a. Roma: Pontificium Institutum Biblicum, 1971.

WEIS, R. D. Biblica Hebraica Quinta and the Making of Critical Editions of the Hebrew Bible. Disponível em: $<$ http://rosetta.reltech.org/TC/vo107/Weis2002.html>. Acesso em: 8 nov. 2021. WIKIPEDIA. Biblia Hebraica (Kittel). Disponível em: $<$ https://en.wikipedia.org/wiki/Biblia_Hebraica_(Kittel)>. Acesso em: 8 nov. 2021. 
Cássio Murilo Dias da Silva

Doutor em Exegese Bíblica pelo Pontifício Instituto Bíblico de Roma Docente de Antigo Testamento nos Cursos de Teologia da Escola de Humanidades da Pontifícia Universidade Católica do Rio Grande do Sul Porto Alegre / RS - Brasil E-mail: cassio.silva@pucrs.br

Recebido em: 23/09/2021 Aprovado em: 08/12/2021 